\title{
INFORMATION IMPEDIMENTS TO INNOVATION OF ON-LINE DATABASE VENDORS ${ }^{1}$
}

\author{
Peter H. Smit ${ }^{2}$ and Manfred Kochen ${ }^{3}$ \\ UTEP Ph.D. Program, The University of Michigan, Ann Arbor, MI 48109, U.S.A.
}

\begin{abstract}
Who decides to improve the information retrieval software for on-line bibliographic or full-text database searching? On what basis do the organizations that make these databases available decide? Are they familiar with known and relatively easy ways to improve retrieval (i.e., of program enhancements that allow for the present kinds of querying without requiring new data structures)? Do they study possible changes in retrieval software in depth or do they just pick some and try them? How important are financial considerations in their decisions to innovate or to wait? These questions are answered on the basis of a telephone survey of 37 on-line vendors.
\end{abstract}

\section{INTRODUCTION}

Since about 1950, a number of document retrieval methods have been proposed, analyzed, developed [1] and occasionally tested [2,3]. Yet, commercial on-line bibliographic search services use relatively few of these methods. Hardly any of the recent advances have found their way into practice. Radecki, in his call for papers to comprise this issue, conjectured that this was due primarily to economic considerations. We decided to explore this conjecture and other possible causes for the low impact of research on information retricval practice.

This interest in the innovation of software is motivated by the forecast of new cheap means of mass information storage, such as boards with preprogrammed chips and optical disk readers with compact disks. Soon these hardware innovations may make microcomputers so cquipped a viable alternative to long distance on-line retrieval for data that don't change too often or for which updates can be readily absorbed. Either of these hardware innovations will require changes in software $[4,5]$.

- Retrieval done on the users' microcomputers will require a method of searching that fits on these smaller machines.

- Results from the chips or compact disks should be integrated with those of one or more floppies, or of a transportable hard disk (e.g., Bernoulli) or even of on-line retrieval of the updates.

Thus, new software will be required. Vendors who are already used to software innovation may have an advantage if they want to make full use of the new hardware.

A survey was conducted to explore what kinds of database vendors are improving their retrieval software and how they do that. Respondents were selected to include 16 "large" vendors (offering at least 10 different databases on-line each) and 21 "smaller" ones (less than 10 databases). They were from both the private and the public sector in the United States. They were selected from one of the directories of on-line databases [6] on the basis of offering either reference or full text databases or both. We asked to speak with someone of the vendor's organization who knows about the retrieval software and its development. The telephone interviews were held in April and May 1986.

\footnotetext{
${ }^{1}$ The support of the Mental Health Research Institute and the Graduate School of Business Administration for the use of their resources is gratefully acknowledged.

${ }^{2}$ Ph.D. student in the Urban, Technological and Environmental Planning Ph.D. Program.

${ }^{3}$ Professor of Information Science, Schools of Medicine and Business Administration, and chair, Sociotechnological Systems in the Planning Ph.D. Program.
} 
The interviews dealt with the vendor's situation and its handling of innovations in retrieval software in general, and with several particular, simple innovations. The latter require no new format for the data or the queries, so that it is not necessary to convert old information or to retrain subscribing users. The innovations that we asked about would be easy to adopt primarily for information services already using keywords and Boolean searching. Hence we interviewed only vendors who feature both keyword and Boolean searching. Keyword searching was taken to mean either: (1) the user can enter any word with the vendor's computer detecting its occurrence in any of the stored entries (open vocabulary) or (2) the user can find out what words are allowed in such search queries and can choose from those subsequently (controlled vocabulary). Boolean searching means that two or more keywords can be combined in the same search query, with at least AND and $O R$ as possible operands.

\section{WHO DECIDES?}

In vendor organizations, decisions about whether or not to go ahead on particular innovations in retrieval software are usually made by groups of people. According to interview results, the number of people that get involved with these decisions varies among the larger vendors (at least 10 databases on line) from 3 to 25 people (average slightly over 8 people) and among the smaller ones (less than 10 different databases per vendor) from 1 to 12 people (average almost 5). We also asked whether the respective vendors are presently contemplating changes in retrieval software. The size of these decision-making groups does not significantly covary with their innovation plans, however.

The members of these groups making decisions about retrieval innovations have been with the vendor organization for varying lengths of time. Table 1 breaks down the vendors into those with younger and older groups that decide on retrieval innovations and shows in addition several aspects of the vendor's general situation that covary clearly.

Table 1 shows that people with more years of experience tend to decide more often for vendors that have been online longer, which have only one kind of database (i.e., either citations or full texts but not both) and where programmers have been with the same vendor longer.

\section{ON WHAT BASIS DO THEY DECIDE?}

We first asked vendors what convinced them to add or not to add three particular innovations. Then we asked what arguments they use for or against innovations in general.

The particular improvements in retrieval that we asked about are ranking the items in a search output, system-user adaptation mechanisms and menu-driven retrieval. Ranking

Table 1. Time on the job of people who decide on software innovations and covarying characteristics of on-line database vendors ( $n=$ number of respondents from which average was obtained)

\begin{tabular}{|c|c|c|}
\hline & \multicolumn{2}{|c|}{$\begin{array}{l}\text { Average length of employment with vendor in the } \\
\text { group that usually get involved in deciding about } \\
\text { retrieval procedures }\end{array}$} \\
\hline & $\begin{array}{l}\text { Less than } 5 \text { years } \\
\qquad(n=23)\end{array}$ & $\begin{array}{l}5 \text { years or more } \\
\quad(n=14)\end{array}$ \\
\hline $\begin{array}{l}\text { How long has the oldest database of } \\
\text { this vendor been on line? }\end{array}$ & $\begin{array}{l}\text { Range: } 0.1-14 \text { years } \\
\text { Average: } 5.6 \text { years } \\
(\mathrm{n}=21)\end{array}$ & $\begin{array}{l}\text { Range: } 4-17 \text { years } \\
\text { Average: } 11.8 \text { years } \\
(n=14)\end{array}$ \\
\hline $\begin{array}{l}\text { Does the vendor offer both reference } \\
\text { and full-text files? }\end{array}$ & Yes, $\mathbf{5 3 \%}$ & Yes, $29 \%$ \\
\hline $\begin{array}{l}\text { How long have the programmers that } \\
\text { usually implement innovations been } \\
\text { with those vendors who do their own } \\
\text { reprogramming? }\end{array}$ & $\begin{array}{l}\text { Range: } 0-5 \text { years } \\
\text { Average: } 2 \text { years } \\
(n=9)\end{array}$ & $\begin{array}{l}\text { Range: } 0-10 \text { years } \\
\text { Average: } 4.6 \text { years } \\
(n=9)\end{array}$ \\
\hline
\end{tabular}


items in a search output refers to putting the retrieved entries in the probable order of priority to the user (e.g., starting with the ones that most closely match the user's query). This is more demanding than placing the entries in alphabetical or chronological order. System-user adaptation mechanisms refer to the machine suggesting additional or better search terms before retrieval is done. It is called "thesaurus aids" at the Department of State, and "paper chase" at the National Library of Medicine, according to some of the other vendors we spoke with. These innovations in retrieval were selected because they have drawn some attention recently [7, pp. 120 and 151] so that vendors could be expected to be familiar with these in some detail. Menu-driven retrieval is a somewhat older innovation that enables the user to interact with the machine by selecting options from menus rather than by using a particular command language. Sometimes the menu-driven routine covers only database selection, and not searching within a database. Sometimes it carries all the way through to handle search queries involving Boolean logic.

The interview results show that reasons for or against acquiring these particular innovations varied from internal ones ("this is our preference") to ones that seem to be completely outside the vendor's control ("had to be compatible with a great diversity of equipment on the user's side"). To analyze this variety we grouped the responses into "business" reasons (e.g., costs, revenues, and attracting a larger share of the market), "service" reasons (e.g., making things easy, satisfying requests for changes from users), and "practical" reasons (e.g., ease of acquisition, technological anticipation). Based on these categories, the appendix at the end of the article lists the reasons given, while Table 2 presents the totals for each kind of reason.

It appears that larger vendors give more reasons for their choices about the selected retrieval innovations than smaller ones do. Business reasons and practical reasons tend to be used against innovation more often than in favor. Service reasons, however, are used for innovation more often than against it. Moreover, small and large respondents alike give more practical reasons than business reasons. This could mean that technical and managerial concerns are more important than economic or financial motives.

Later in the interview, responding vendors were asked in general about the arguments they typically use in favor or against any particular innovation in retrieval software. These are arguments not in the sense of disputes or battles (not necessarily, anyway) but in the sense of reasons for choosing to try a potential improvement or not. According to the interviews these vary from idealistic arguments ("how will it look to the nontechnical user") to hard-nosed business arguments ("return on investment and to remain competitive"). Larger vendors mentioned an average of about four arguments and smaller ones three. The kinds of arguments given (financial, economic, service, practical, or intentional ones) differ between the larger and smaller vendors (seen in Table 3). More of the larger vendors state business arguments $(94 \%)$ than the smaller ones $(68 \%)$ while more of the smaller vendors state intentional arguments $(32 \%)$ than larger ones do (12\%).

It is interesting to note which larger and smaller vendors mention the middle category of semibusinesslike, client-oriented service arguments. Now that the technical and market fcasibility of database vending have been proven, service may well be the most decisive factor in further growth. Yet service arguments may not come naturally either to those with business backgrounds (financial or microeconomic emphasis) or to the programmers (tech-

Table 2. Numbers of several kinds of reasons given for and against adopting each of three particular innovations. $(\mathrm{L}=$ stated by large vendors $(10$ or more dababases on line), $\mathrm{S}=$ stated by small vendors)

\begin{tabular}{|c|c|c|c|c|}
\hline Reasons & For & Against & & Total \\
\hline Business & $9(L: 5, S: 4)$ & $18(\mathrm{~L}: 11, \mathrm{~S}: 7)$ & & $27(23 \%)$ \\
\hline Service & $26(\mathrm{~L}: 16, \mathrm{~S}: 10)$ & $17(\mathrm{~L}: 8, \mathrm{~S}: 9)$ & & $43 \quad(37 \%)$ \\
\hline \multirow[t]{2}{*}{ Practical } & $16(\mathrm{~L}: 7, \mathrm{~S}: 9)$ & $29(\mathrm{~L}: 18, \mathrm{~S}: 11)$ & & $45 \quad(39 \%)$ \\
\hline & & & TOTAL & $115(100 \%)$ \\
\hline
\end{tabular}


Table 3. Proportions of vendors that typically use various kinds of arguments for or against any particular innovation ( $n=$ number of respondents on which $\%$ is based)

\begin{tabular}{lcc}
\hline & $\begin{array}{c}\text { Larger vendors } \\
(10 \text { databases } \\
\text { or more) }\end{array}$ & $\begin{array}{c}\text { Smaller vendors } \\
\text { (fewer than } \\
10 \text { databases) }\end{array}$ \\
\hline $\begin{array}{l}\text { Percentage of vendors that use } \\
\text { business-type arguments } \\
\text { (including financial) }\end{array}$ & $\begin{array}{l}94 \% \\
(n=16)\end{array}$ & $68 \%$ \\
$\quad \begin{array}{l}\text { Fraction of above that also } \\
\text { uses service arguments }\end{array}$ & $73 \% \%$ & $46 \%$ \\
$\begin{array}{l}\text { Percentage of vendors that use } \\
\text { financial arguments }\end{array}$ & $(n=15)$ & $(n=13)$ \\
$\begin{array}{l}\text { Percentage of vendors that use } \\
\text { service arguments }\end{array}$ & $56 \%$ & $42 \%$ \\
Percentage of vendors that use & $(n=16)$ & $(n=19)$ \\
technical arguments & $75 \%$ & $58 \%$ \\
$\quad \begin{array}{l}\text { Fraction of above that also } \\
\text { uses service arguments }\end{array}$ & $(n=16)$ & $42 \%$ \\
Percentage of vendors that use & $50 \%$ & $(n=19)$ \\
intentional arguments & $(n=16)$ & $50 \%$ \\
\hline
\end{tabular}

nical or practical emphasis) who are likely to be involved as vendors. Table 3 shows the share of vendors who mention businesslike arguments who also mention these serviceoriented ones, and the portion of vendors who mention technical arguments who also mention service-oriented arguments.

It appears in Table 3 that the larger vendors, who consider business or technical arguments, are more likely to also be aware of service-oriented arguments than small vendors are. Moreover, it appears that respondents who stated technical arguments also mentioned service arguments more often than respondents who stated business arguments. This, again, could mean that being businessminded is not the only nor the better guarantee for having a strong service orientation and, thus, being attractive to new kinds of users.

\section{DO THE VENDORS SEEM KNOWLEDGEABLE ABOUT INNOVATIONS?}

Several questions in the telephone interviews explored whether the vendors are familiar with particular new routines in information retrieval. Before asking whether and why they had adopted the three innovations, responses to which are reported in the above, we asked if they had heard of ranking items in the search result, of system user adaptation (or thesaurus aids), and of the older innovation of menu driven retrieval.

Familiarity with these innovations is indicated in Table 4 with respect to the vendor's size. Beyond familiarity in the sense of having heard of the concept, what may be more important as a prerequisite to adopting these enhancements is familiarity with versions that are easy to implement. By easy we mean that they can be superimposed on existing data structures and allow for Boolean search queries as the users are accustomed to. If data structures had to be altered in order to accommodate the improvement, all current data would have to be reentered or converted. If search questions involving several keywords with ANDs, ORs, or NOTs in between could no longer be processed, current subscribers might feel let down. Vendors can be expected to decide against innovations unless they are convinced that the innovation is compatible with the existing data formats and Boolean logic. The setback lines of Table 4 show, of the vendors who said they were familiar with particular innovations, the proportion that understood these to be easy in this sense. Here even "don't know" responses are interpreted as showing uncertainty about the possibility to keep the innovation simple and practical. 
Table 4. Proportion of vendors that understand various characteristics of particular retrieval innovations ( $n=$ number of respondents on which $\%$ is based)

\begin{tabular}{lcc}
\hline & $\begin{array}{c}\text { Larger vendors } \\
\text { (10 databases } \\
\text { or more) }\end{array}$ & $\begin{array}{c}\text { Smaller vendors } \\
\text { (fewer than } \\
10 \text { databases) }\end{array}$ \\
\hline Familiar with ranking items in a search output & $\begin{array}{c}86 \% \\
(n=14)\end{array}$ & $\begin{array}{c}48 \% \\
(n=21)\end{array}$ \\
$\begin{array}{l}\text { Fraction of the above that understands: } \\
\text { Item ranking not to involve weights assigned by } \\
\text { information suppliers }\end{array}$ & $\begin{array}{c}83 \% \\
(n=12)\end{array}$ & $\begin{array}{c}67 \% \\
(n=9)\end{array}$ \\
Item ranking not to require the rating of keywords & $\begin{array}{c}45 \% \\
(n=11)\end{array}$ & $\begin{array}{c}44 \% \\
(n=9)\end{array}$ \\
$\begin{array}{l}\text { Familiar with system user adaptation } \\
\text { Fraction of the above that understands: } \\
\text { System-user adaptation not to involve setting back } \\
\text { permanently items that are rarely retrieved }\end{array}$ & $\begin{array}{c}50 \% \\
\text { System-user adaptation not to involve rating of items }\end{array}$ & $\begin{array}{c}88 \% \\
(n=16)\end{array}$ \\
$\begin{array}{l}(n=8) \\
\text { Familiar with menu-driven retrieval }\end{array}$ & $\begin{array}{c}63 \% \\
(n=8)\end{array}$ & $\begin{array}{c}83 \% \% \\
(n=6)\end{array}$ \\
$\begin{array}{l}\text { Fraction of the above that understands: } \\
\text { Menu-driven retrieval to be workable even when } \\
\text { Boolean logic is to be used }\end{array}$ & $100 \%$ & $50 \%$ \\
\hline
\end{tabular}

Table 4 shows, first of all, that larger vendors have more complete and more practical knowledge of the selected innovations in retrieval software than smaller vendors do. Moreover, given that menu-driven retrieval is familiar whilc ranking of items in a search output and system-user adaptation mechanisms are less familiar, Table 4 also shows that a complete and practical understanding of innovations in retrieval is more common for the more familiar innovation. One might think it is obvious that more details are known about things that are more familiar. This is still an interesting finding because it is derived from the answers of people who say, in all cases, that they are familiar with these innovations. So, the problem is not only that they know less about innovations that are less familiar in general, but also that they don't realize there is more to know. This shape of the problem has been understood for some time [8] and was stressed again at a recent meeting of information science professionals [9].

The more general finding is that there are large gaps in knowledge of practical innovations among on-line database vendors. Although we asked to speak with people knowledgeable about retrieval software at the start of every interview, only about twothirds of our respondents were familiar with ranking items in a search output and only onethird recognized the concept of system user adaptation even after a brief explanation. In this regard, on-line vendors differ, we believe, from most high technology industries, where news about innovations is pursued with much dedication.

\section{DO VENDORS PREPARE INNOVATIONS?}

When ideas for enhancement in retrieval software come along, do the vendors debate, assess, and perhaps test these before a final decision is made? Or do they just decide quickly or follow the suggestions of software retailers? In the telephone interviews we asked "What is typically done to make the arguments for or against an innovation as clear as possible?" This open question was followed by specific questions regarding some 21 possible activities for that purpose. 
Responses to the open question involved, on average, 2.4 activities varying from a simple "sit and talk" to a seven-step procedure including "budgeting" (not for implementing the innovation but for the process of testing and debating it). The responses are divided into:

- Market-oriented activities, presumably to clarify the financial (revenue), business, and service aspects of an innovation,

- Programming-oriented activities probably to arrive at technical specifications and cost estimates, and

- Discussion-oriented activities possibly aimed at bolstering self-confidence, setting priorities, and generating commitment.

This categorization has been applied in Table 5 .

It is interesting to note which of the vendors mention more than one kind of activity in preparation for retrieval innovations. Depending on the particular kind of combination, this integration of concerns is apparent with only $7 \%$ to $27 \%$ of the larger vendors (at least 10 databases on line) and with as many as $32 \%$ to $47 \%$ of the smaller ones (fewer than 10 databases offered). One could conclude that respondents from smaller vendors appear to have a more balanced perspective on retrieval improvement.

The answers regarding 21 specific activities to prepare software improvements are shown in Table 6.

It appears that larger vendors engage in all of these activities more often than smaller vendors (all except estimating operational costs, and for that one the reverse holds by only $1 \%$ ). Yet, with the smaller vendor appearing to have a less fragmented, more balanced perspective, one wonders if the effect of all these activities is always for the better.

\section{DOES MONEY DECIDE?}

Whether financial considerations tend to prevail over other concerns can be seen most clearly from the answers to specific questions asked regarding the three particular innovations mentioned before. In addition, the level of priority of financial considerations may be deduced from answers to the open-ended question about arguments typically used when considering potential innovations.

First, consider the response to the short series of specific questions asked about each of the three innovations (item ranking in retrieval results, system-user adaptation mechanisms, and menu-driven retrieval) mentioned earlier. These questions include financial and other considerations. The responses, providing some insight in the relative importance of financial considerations, are listed by innovation in Table 7.

The first part of Table 7 deals with vendors who did implement the particular innovation and who are experiencing its financial and other consequences. The key to their propensity to further innovate, we suggest, is the question of whether they are satisfied with

Table 5. Proportion of vendors engaged in various kinds of activities to prepare innovations in retrieval software ( $n=$ number of respondents on which $\%$ is based)

\begin{tabular}{lcc}
\hline & $\begin{array}{c}\text { Larger vendors } \\
\text { (10 or more } \\
\text { databases) }\end{array}$ & $\begin{array}{c}\text { Smaller vendors } \\
\text { (fewer than 10 } \\
\text { databases) }\end{array}$ \\
\hline Market-oriented activities & $47 \%$ & $58 \%$ \\
Programming-oriented activities & $47 \%$ & $58 \%$ \\
Both market and programming oriented & $13 \%$ & $42 \%$ \\
Discussion-oriented activities & $60 \%$ & $79 \%$ \\
Both market and discussion oriented & $13 \%$ & $47 \%$ \\
Both programming and discussion oriented & $27 \%$ & $42 \%$ \\
All three & $7 \%$ & $32 \%$ \\
\hline
\end{tabular}


Table 6. Proportions of vendors that engage in selected preparatory activities ( $n=$ number of respondents on which $\%$ is based)

\begin{tabular}{|c|c|c|}
\hline & $\begin{array}{l}\text { Larger vendors } \\
\text { (10 databases } \\
\text { or more) }\end{array}$ & $\begin{array}{l}\text { Smaller vendors } \\
\text { (fewer than } \\
10 \text { bases) }\end{array}$ \\
\hline 1. Study the market & $88 \%(n=16)$ & $57 \%(n=21)$ \\
\hline 2. Study the competition & $94 \%(n=16)$ & $76 \%(n=21)$ \\
\hline 3. Assess longevity of innovation & $63 \%(n=16)$ & $40 \% \quad(n=20)$ \\
\hline 4. Assess if innovation replaces or complements existing features & $100 \%(n=16)$ & $75 \%(n=20)$ \\
\hline 5. See how retrieval is done now & $88 \%(n=16)$ & $62 \%(n=21)$ \\
\hline $\begin{array}{l}\text { 6. See how retrieval results are being used (in user's further } \\
\text { processing) }\end{array}$ & $88 \%(n=16)$ & $62 \%(n=21)$ \\
\hline 7. Formulate system requirements & $88 \%(n=16)$ & $81 \%(n=21)$ \\
\hline 8. Prototyping & $80 \%(n=15)$ & $70 \%(n=20)$ \\
\hline 9. Hire out research & $25 \%(n=16)$ & $19 \%(n=21)$ \\
\hline 10. Hire out development (e.g., contract out prototype refinement) & $50 \%(n=16)$ & $45 \%(n=20)$ \\
\hline 11. Study feasibility (of particular ideas for innovation in retrieval) & $63 \%(n=16)$ & $48 \%(n=21)$ \\
\hline 12. Study user studies done elsewhere & $94 \%(n=16)$ & $62 \%(n=21)$ \\
\hline 13. Cost planning for $R \& D$ & $81 \%(n=16)$ & $62 \%(n=21)$ \\
\hline 14. Estimate operational costs of innovations (once implemented) & $75 \%(n=16)$ & $76 \%(n=21)$ \\
\hline $\begin{array}{l}\text { 15. Monitor quality of computer programming (of programmers } \\
\text { who implement most of the innovations) }\end{array}$ & $940 \%(n-16)$ & $=20)$ \\
\hline 16. Develop programming skills & $87 \%(n=15)$ & $52 \%(n=19)$ \\
\hline $\begin{array}{l}\text { 17. Monitor quality of management (especially of managers who } \\
\text { decide on the adoption of innovations) }\end{array}$ & $81 \%(n=16)$ & $57 \%(n=20)$ \\
\hline 18. Develop management skills & $94 \%(n=16)$ & $75 \%(n=20)$ \\
\hline $\begin{array}{l}\text { 19. Anything else with respect to preparing for innovations in } \\
\text { retrieval }\end{array}$ & $81 \%(n=16)$ & $52 \%(n=20)$ \\
\hline 20. More activities the respondent cared to mention & $50 \%(n=16)$ & $35 \%(n=20)$ \\
\hline 21. Still more & $19 \%(n=16)$ & $15 \%(n=20)$ \\
\hline
\end{tabular}

these particular innovations. The proportion of positive answers to that question is high, unlike the proportions on the preceding questions about financial indicators, but more similar to the proportions on the subsequent question about perceived user satisfaction. It appears that vendor satisfaction co-varies more closely with user satisfaction than with financial considerations.

While this finding holds for vendors who implemented any of the three innovations we asked about, a similar but weaker finding holds for vendors who did not so innovate. The last part of Table 7 reports some of their answers, where the key to their interest in innovation, we suggest, is the question whether they think suggestions for implementing these particular innovations may come up again soon. The portion of positive answers hovers around two-thirds. Again, this is higher than the scores on preceding questions about financial expectations. It is not as high as the subsequent items on practical and programming aspects. It appears, then, that financial considerations are not all that leads vendors to expect to have to discuss particular innovations soon but that more practical and computer concerns help to set that level of expectation as well.

Next, consider responses to the open-ended question "What arguments are typically used for or against a particular innovation?" Differences between large and small vendors in their response to this question were discussed in connection with Table 3. Inasmuch as financial arguments are involved, these do not appear to cluster among the larger vendors. Later in the interview, respondents were asked if they were contemplating either minor or major changes in retrieval software. The top part of Table 8 tries to cross-tabulate the kinds of arguments they mention as a criteria for any innovation on the one hand with the presence of plans for innovations on the other.

It appears that fewer of the vendors contemplating innovations mention financial arguments $(36-43 \%)$, whereas more of the ones that are not contemplating innovations mention financial considerations $(67 \%)$. This would indicate that having financial arguments in the foreground of vendors' minds reduces the probability of their considering innovations by a factor of about one and a half (see first remark in table). 
Table 7. Responses to selected financial and other questions regarding three particular innovations in retrieval software

\begin{tabular}{cccc}
\hline & $\begin{array}{c}\text { Item ranking } \\
\text { in retrieval } \\
\text { results }\end{array}$ & $\begin{array}{c}\text { System-user } \\
\text { adaptation } \\
\text { (thesaurus aid) }\end{array}$ & $\begin{array}{c}\text { Menu- } \\
\text { driven } \\
\text { retrieval }\end{array}$ \\
\hline
\end{tabular}

( $n=$ number of respondents who offer it and who gave clear answers)

Charging users extra for it

Charging information suppliers extra because it is offered

Makes searching inside a file take longer

Makes the user stay online longer

Users come back more often

Appears to reduce the need for customer support

Makes service available to new kind of customer

VENDOR SATISFIED WITH IT

(somewhat, very or completely)

Users satisfied

$\begin{array}{rrc}0 \% & 0 \% & 4 \% \\ (n=5) & (n=3) & (n=23) \\ 20 \% & 0 \% & 0 \% \\ (n=5) & (n=2) & (n=23) \\ 33 \% & 67 \% & 33 \% \\ (n=3) & (n=3) & (n=21) \\ 75 \% & 67 \% & 63 \% \\ (n=4) & (n=3) & (n=19) \\ 33 \% & 100 \% & 81 \% \\ (n=3) & (n=2) & (n=16) \\ 25 \% & 50 \% & 74 \% \\ (n=4) & (n=2) & (n=23) \\ 20 \% & 0 \% & 82 \% \\ (n=5) & (n=3) & (n=22) \\ 100 \% & 100 \% & 95 \% \\ (n=5) & (n=3) & (n=21) \\ 100 \% & 100 \% & 94 \% \\ (n=5) & (n=3) & (n=18)\end{array}$

( $m=$ number of respondents who do not offer it, and who gave clear answers)

$\begin{array}{ccc}13 \% & 40 \% & 60 \% \\ (m=15) & (m=10) & (m=10) \\ 0 \% & 0 \% & 8 \% \\ (m=14) & (m=11) & (m=12) \\ 63 \% & 70 \% & 70 \% \\ (m=16) & (m=10) & (m=10) \\ 88 \% & 91 \% & 100 \% \\ (m=16) & (m=11) & (m=12) \\ 94 \% & 92 \% & 100 \% \\ (m=16) & (m=12) & (m=12) \\ 70 \% & 90 \% & 100 \% \\ (m=10) & (m=10) & (m=12)\end{array}$

Similar cross-tabulation in the lower part of Table 8 shows that familiarity with recent innovations, such as ranking in a retrieval result and system-user adaptation, correlates with vendors' planning any innovations in retrieval. Knowing these particular innovations appears to increase the probability of the vendor actually contemplating any kind of retrieval innovations by a factor of up to about two. Admittedly, there are not many vendors who contemplate no improvements in retrieval at all, so this finding is based on rather small numbers. From the available evidence, it appears that whether a vendor is considering changes in retrieval can be predicted by that vendor's familiarity with innovation sonewhat better than by their mentioning financial concerns when asked the open question about arguments they typically used.

Taking all the findings about financial arguments together then, lack of concern about finances does not appear to be as important an impediment as lack of information about potential retrieval improvernents among the vendors we interviewed. This is apparent especially from the questions about vendor's experience and expectation of three specific innovations (Table 7) and somewhat from the questions about their criteria for and knowledge of any innovation (Table 8). 
Table 8. Proportions of vendors planning certain innovations in retrieval software and the types of arguments they say they use with respect to any particular innovation ( $n=$ number of respondents on which the $\%$ are based)

\begin{tabular}{|c|c|c|c|c|c|}
\hline & $\begin{array}{l}\text { Major } \\
\text { changes } \\
(n=14)\end{array}$ & $\begin{array}{c}\text { Minor changes } \\
\text { (no reformatting) } \\
(n=23)\end{array}$ & $\begin{array}{c}\text { Any } \\
\text { changes* } \\
(n=27)\end{array}$ & $\begin{array}{l}\text { No plans } \\
\text { for change } \\
(n=6)\end{array}$ & Remarks \\
\hline Business arguments & $71 \%$ & $74 \%$ & $81 \%$ & $67 \%$ & \multirow{3}{*}{$\frac{67}{41}=1.63$} \\
\hline Financial & $36 \%$ & $43 \%$ & $41 \%$ & $67 \%$ & \\
\hline Business, nonfinancial & $50 \%$ & $61 \%$ & $59 \%$ & $33 \%$ & \\
\hline Service arguments & $71 \%$ & $78 \%$ & $74 \%$ & $33 \%$ & \\
\hline Practical arguments & $50 \%$ & $52 \%$ & $48 \%$ & $50 \%$ & \\
\hline Intentional arguments & $21 \%$ & $22 \%$ & $22 \%$ & $17 \%$ & \\
\hline \multicolumn{6}{|l|}{ Familiar with } \\
\hline Item ranking & $77 \%$ & $69 \%$ & $72 \%_{0}$ & $37 \%$ & \multirow{3}{*}{$\frac{17}{37}=1.95$} \\
\hline System-user adaptation & $36 \%$ & $41 \%$ & $38 \%$ & $25 \%$ & \\
\hline Menu-driven retrieval & $100 \%$ & $100 \%$ & $100 \%$ & $100 \%$ & \\
\hline
\end{tabular}

* "Any changes" includes a few where the nature of changes was unclear, but it is less than the sum of major and minor changes because many vendors had plans for both kinds.

\section{CONCLUDING DISCUSSION}

Summarizing the findings, we see that teams with more years of experience work for vendors that have been on-line longer, that have either reference or full-text files, but rarely both, and that have programmers on their staff who have been there longer (see Table 1). These teams decide primarily on the basis of service reasons (including customer convenience and requests for change) and practical reasons (including ease of implementation and technological forecasts) (see Table 2). Moreover, if they decide favorably about an innovation it is more often for service reasons while they decide against it more often for business reasons (including costs, revenues, and market share). Larger vendors are aware of more reasons than smaller ones. Business reasons receive relatively more attention from larger vendors and intentional reasons (assistance with particular data, user groups, functions, or general simplicity) more from smaller vendors. If the rationale of larger vendors includes business or practical arguments, it is likely to also include service arguments more often that is the case among smaller ones (see Table 3). Most importantly, there is an important lack of knowledge about potential innovations (see Table 4). Depending on the particular enhancement, only one- to two-thirds of the respondents were familiar with these, even though all of them have been discussed in the literature for some time. There is probably also lack of familiarity with fundamentals [10]. Only three-quarters of those who are familiar with the innovations as concepts know how to make these enhancements practical. That could be due to customers not having expected too much in the way of sophisticated retrieval procedures, and due to vendors stressing delivery of a full subjectmatter spectrum rather than improving search procedures.

Furthermore, larger vendors are found to be more fragmented than smaller ones in their perspective on why to innovate or wait. Few mention both market-oriented and computer-programming-oriented activities in preparing for innovation (see Table 5). However, larger vendors are more active than smaller ones in investigating potential improvements (engage in greater number of preparatory activities) (see Table 6). To conclude this summary of findings, the pursuit of innovations does not co-vary with the use of financial indicators or expectations (see Table 7) as much as the use of indicators of user satisfaction, expectations about practical aspects, with being informed about the enhancements in concept, and about easy algorithms for them (see Table 4). Apparently poor informa- 
tion about the possibilities is the main impediment to innovation of retrieval software (see also Table 8 ).

We suggest that database vendors look more carefully at their clients' searching behavior and clients' behavior in response to price changes. Although innovation may not pay for itself within months (many vendors said they just can't think of their improvements in that way), service development should not stagnate or go unchecked for lack of feedback. If revenues are not the appropriate signal, it is easy to develop other forms of feedback in this information industry. At present, however, many vendors do not monitor the frcquency of use of keywords, of Boolean connectives, of commands or menu options on a regular basis. This can be done either by capturing the entered commands [11] or by administering a short questionnaire online at the end of a random sample of the searches [12] or both. Because, with respect to innovations, vendor satisfaction covaries highly with user satisfaction (see Table 7), the vendors can be expected to take seriously such tendencies as:

- Users switching to competitors if the price is only slightly better (especially the evening users),

- Users searching more on stand-alone, paid-for, optical-disk systems than on monitored pay-as-you-go on-line systems, almost regardless of the searching qualities, substantive contents or auxiliary applications offered.

If financial arguments do not shape the innovation behavior of vendors, they do seem to shape the behavior of database users. Yet it may be that paying customers are not as sensitive to prices as to predictability of cost and to the method of payment, which structure the relation between the organizations that carry the subscription and the end users.

Acknowledgment - The help and expertise of Betty Wolverton of the School of Business Administration in the preparation and revisions of this manuscript was a great value, as were the detailed, constructive comments of Tadeusz Radecki.

\section{REFERENCES}

1. van Rijsbergen, C.J. Information retrieval. London and Boston: Butterworths; 1979.

2. Sparck Jones, K., editor. Information retrieval experiment. London and Boston: Butterworths; 1981.

3. Blair, D.C.; Maron, M.E. An evaluation of retrieval effectiveness for a full-text document retrieval system. Communications of the ACM, 28(3): 289-99; 1985 March.

4. Chen, C. Microwatch. Microcomputers for Information Management, 2(2): 129-134, 1984 June.

5. Sieck, S.K. Database publishing applications of optical video disks. In: Williams, M.E.; Hogan, T.H., editors. National on-line meeting proceedings 1983. Medford, NJ; Learned Information, Inc.; 1983: 499-502.

6. Cuadra. Directory of online databases. 7(1). New York: Elsevier; 1986 January.

7. Salton, G.; McGill, M.J. Introduction to modern information retrieval. New York: McGraw-Hill; 1983.

8. Kochen, M. Integrative mechanisms in literature growth. Westport, CT: Greenwood; 1974.

9. Dordick, H. Market research in the information economy, we don't know what we don't know. In: 1984 Challenges to an information society, proceedings of ASIS. White Plains, NY: Knowledge Industry Publications, Inc.: 1984: 243 .

10. Kochen, M. Principles of information retrieval. Los Angeles, CA: Melville/Wiley; 1974.

11. Tolle, J.E. Monitoring usage of on-line information systems, NLM catline database. 1984 challenges to an information society, proceedings of ASIS annual meeting. White Plains, NY: Knowledge Industry Publications, Inc.; 1984: 126-29.

12. Stancik, 1.; Harmeyer, K. A microcomputer application in information services evaluation. In: Williams, M.E.; Hogan, T.H., editors. National on-line meeting proceedings 1983. Medford, NJ: Learned Information Inc.; 1983: 523-530.

\section{APPENDIX}

Reasons given by vendors to add or not to add selected innovations $(L=$ stated by larger vendors ( 10 databases on-line or more), $\mathrm{S}=$ stated by smaller vendors) 


\section{ITEM RANKING IN A SEARCH OUTPUT}

REASONS FOR

$($ total $=0)$

\section{REASONS AGAINST}

\section{Business Reasons}

Low priority (L), was implemented and little used and dropped (L), [need to] improve substance [data] rather than [searching] procedures (L), not as urgent as creating text fields [another innovation] (S), not as urgent as searching for word pairs (S). (total $=5$, $3 \mathrm{~L}+2 \mathrm{~S})$

\section{Service Reasons}

Wanted to pinpoint items for the user (S). (total $=1, \mathrm{~S}$ )

[Paying] customers are not asking for this change (L), no users [maybe end users rather than paying intermediaries or subscribing institutions] ask for it (L), users don't browse [in this particular database] (S), too complex (S), users are looking for specific information (S). (total $=5,2 \mathrm{~L}+3 \mathrm{~S}$ ).

\section{Practical Reasons}

Was already there [in purchased retrieval software] $(L+2 S)$, it is the only way to handle contents [of this particular database] (S). (total $=4, \mathrm{~L}+$ 3S)
Is hard to develop (L), hard to implement (L), still refining the algorithm (L), need to know articles before ranking them [criteria for ranking difficult to specify ahead of time] (L), queries are not remembered [apparently not even during the search, so the computer cannot rank retrieved items against the query] (L), order [of display can be adjusted] already by scan before display (L), the sets to rank can get so large $(\mathrm{L})$, present software too big [to make changes easily] (S), it is not good enough $(\mathrm{S})$. (total $=9,7 \mathrm{~L}+2 \mathrm{~S}$ ).

\section{SYSTEM USER ADAPTATION}

REASONS FOR

Business Reasons

$($ total $=0)$

\section{REASONS AGAINST}

Other priorities $(2 \mathrm{~L}+\mathrm{S})$, cost $(\mathrm{L}+$ $2 S$ ), would require feasibility study (L), hold off until next version of basic retrieval program $(\mathrm{L})$, need expert intermediaries (people) (S). (total $=9$, $5 \mathrm{~L}+4 \mathrm{~S})$

\section{Service Reasons}

Customers asked for it (L), kind of users [apparently not all users are familiar with the assigned retrieval terms for this particular database] (S), foreign users thought of it (S). (total 3, $(\mathrm{L}+2 \mathrm{~S})$
Not asked by users (L), [without it, it is easier to] produce at lcast some hits more often (S), local users don't need it (S), too complex for users (S). (total = $4, \mathrm{~L}+3 \mathrm{~S})$ 
REASONS AGAINST

\section{Practical Reasons}

Kind of data [this particular database apparently can be approached only through successive approximations] (S). (total $=1, \mathrm{~S}$ )
Development takes time (L), testing takes time (L), machines could not interpret language [to suggest better search terms] at the time [when the retrieval software was obtained] (L), matter of general approach [apparently the philosophy is this vendor does not permit it] (L), would require prototype (L), misspellings already dealt with in other way [this vendor does not expect much of it besides handling misspelled queries] (L), database too small (S), computer limitations (S), not clear how it works (S), items are so short that users can select by reading them [as a procedure for improving the specification of a search, it is not thought to be worthwhile] (S), never thought of it (S). (total $=11,6 \mathrm{~L}+5 \mathrm{~S})$

\section{MENU-DRIVEN RETRIEVAL}

REASONS FOR

\section{REASONS AGAINST}

\section{Business Reasons}

Expanding market [more untrained subscribers for whom menus can really make a difference] $(2 L)$, it shows and explains all our services (2S), more [untrained] users (L), had computer time left over at night [menu system apparently slower but made available after working hours] (L), reduces training costs $(\mathrm{L})$, preference of CD ROM developer (S), others offer it (S). (total $0,5 \mathrm{~L}+4 \mathrm{~S}$ )
[Would require] user training (L), vendor also features cataloguing service in which menus would not be useful (L), users are a stable group [apparently trained well enough not to need menus] (L), overhead not worth it (S). (total $=4,3 \mathrm{~L}+\mathrm{S}$ )

\section{Service Reasons}

Ease of use $(\mathrm{L}+5 \mathrm{~S})$, requests from users (2L), more end users [usually less trained than intermediaries, doing simpler queries and not searching often] (2L), unsophisticated users (2L), users don't learn commands (L), fewer intermediaries $(\mathrm{L})$, [it is attractive for] new users (L), users friendly (L), all kinds of users (L), use without manuals (L), easy for nonspecialists (L), quicker start for new users (L), featured even in certain operating systems [couldn't ignore general trend] (S), good for user training $(\mathrm{S}) .($ total $=22,15 \mathrm{~L}+7 \mathrm{~S})$
Most users are regulars [frequent users find menus slow] (L), users prefer present commands (L), user's priority for $\mathrm{PC}$ and not menu (L), some users get tired of menus (L), service not aimed at public access (S), user would have to know keywords [meaning of menu options not immediately clear] (S), using menus takes too long even though it would reduce typing errors (S). (total $=8,5 L+3 S$ ) 


\section{Practical Reasons}

Was already there [as option in purchased retrieval software] $(2 \mathrm{~L}+2 \mathrm{~S})$, data are clearly categorized (L), series of menus need not go very deep (L), possible to let experienced users bypass the menus (L), started it for selecting applications [menus already used outside the database] (L), it is industry standard (S), own preference (S), option for it was offered by developer of the initial software [as an upgrade] (S). (total $=11,6 \mathrm{~L}+5 \mathrm{~S})$
Many users still have teletypes (2L), why change (L), most users do not have full screen PC [meaning halfscreen one? or no full screen cursor control?] (L), thinking of [and waiting to develop] AI front-end (L), has to be compatible with variety of hardware on user's side ( $\mathbf{S}$ ), at first terminals couldn't make small changes in a display [e.g., moving cursor to an option on a menu] but now more can (S), working on it now [implementation speed is bottleneck rather than business or service concerns] (S), left it to a consultant [apparently this vendor considered the issue too technical to respond to directly] (S). (total 9, 5L + 4S) 